\title{
ÉTICA E ESTÉTICA DA POESIA MARGINAL
}

\author{
Debora Priscila Arevalo Gutierrez ${ }^{1}$ \\ Vitor $\mathrm{Cei}^{2}$
}

\begin{abstract}
Resumo: A antologia 26 poetas hoje, organizada e publicada por Heloisa Buarque de Hollanda em 1976, evidencia que ética e estética são duas dimensões absolutamente imbricadas na poesia marginal brasileira dos anos 1970. Este artigo tem como objetivo identificar e examinar as principais características éticas e estéticas da crítica que a poesia marginal fez da ditadura militar no Brasil. Destaca-se que a poesia marginal recusava o status quo, a favor da experimentação e da resistência, de modo que a intersecção entre estética e ética assume grande relevância política, como pode ser verificado na antologia. Conclui, preliminarmente, que a experiência estética passa a se constituir uma via de acesso para a vida ética.
\end{abstract}

Palavras-chave: crítica social; ditadura militar; poesia marginal.

\begin{abstract}
The anthology 26 poetas hoje [26 poets today], edited and published by Heloisa Buarque de Hollanda in 1976, shows that Ethics and Aesthetics are two absolutely connected dimensions of the Brazilian marginal poetry during the 1970s. This article aims to identify and examine the most important ethical and aesthetical characteristics of the marginal poetry critics to the military dictatorial times in Brazil. Stands out that the marginal poetry refused the status quo, in favor of experimentation and resistance, so that the connection between esthetics and ethics acquired political relevance, as one can verify in the anthology. Conclude, preliminarily, that the aesthetic experience comes to constitute itself as a pathway into ethical life.
\end{abstract}

Keywords: social criticism; military dictatorship; marginal poetry;

INTRODUÇÃO

A chamada "poesia marginal" dos anos 1970, a despeito de seu processo de canonização, ainda sofre com a pecha de "poesia ruim", antiliterária e inculta (SIMON, DANTAS, 1985). Não obstante, como já alertava Charles Baudelaire, nem todas as respostas estão nos maiores autores do cânone artístico. Há nos pequenos, nos marginais e por vezes nos esquecidos poetas muito sobre a época em que produziram, o que por si só representa um relevante conhecimento sobre o mundo e sobre as visões de mundo possíveis: "os poetae minores possuem algo de bom, de sólido e de delicioso" (BAUDELAIRE, 1996, p. 7-8).

O conceito de marginália surgiu em 1968, com a bandeira-poema "Seja marginal, seja herói", de Hélio Oiticica. Como o termo pressupõe, o movimento propôs uma ética (política de vida) e uma

\footnotetext{
${ }^{1}$ Graduanda em Letras-Português na Universidade Federal de Rondônia. Ex-bolsista PIBIC/CNPq. Residente bolsista na EEEFM São Luiz, em Porto Velho. E-mail: deboraarevalo2412@ @otmail.com

${ }^{2}$ Doutor em Estudos Literários pela UFMG. Professor do Departamento de Línguas Vernáculas da Universidade Federal de Rondônia. E-mail: vitorcei@gmail.com
} 
estética "desviantes", contraculturais, alternativas, opondo-se ao famigerado sistema conservador e ditatorial imposto no Brasil.

A geração mimeógrafo, como ficou conhecida, produzia, editava e vendia suas obras sem recorrer a editoras, ou seja, à margem da indústria cultura, recusando as supostas facilidades que o sistema proporcionava aos escritores e artistas, de forma que também podia controlá-los. Posicionando-se contra o estabelecido, os marginais inventavam seus próprios meios de publicação, oferecendo alternativas ao modo de produção capitalista.

Representativos da marginalia, os poemas que serão analisados neste artigo abordam as crises cotidianas com desbunde, coloquialidade e crítica social, tirando a poesia de sua torre de marfim, levando-a às ruas, pois "lugar de poesia é na calçada" (SAMPAIO, 1976, s. p.). Utilizar-se de palavras de baixo calão, retratar obscenidades e transgredir os valores morais a partir da palavra são marcas registradas da poesia marginal. Desta maneira, a arte combatia o sistema sem pegar em armas, como a militância, e sem se relacionar tão explicitamente com as formas de produção da indústria cultural, como faziam os tropicalistas - ainda que "atendendo amplamente às faixas de consumo jovem" (SIMON, DANTAS, 1985, p. 49).

$\mathrm{Na}$ antologia 26 poetas hoje, publicada por Heloisa Buarque de Hollanda em 1976, encontramos uma memória das tensões que ocorriam no Brasil dos anos de ditadura militar. Nosso objetivo geral é identificar e examinar as principais características éticas e estéticas da crítica que a poesia marginal fez da ditadura militar no Brasil. Como objetivos específicos, planejamos esclarecer que ética e estética são duas dimensões absolutamente atreladas uma a outra na poesia marginal, codificando relações de poder e dominação, em oposição às ideologias, instituições e práticas hegemônicas.

\section{O NASCIMENTO DA MARGINÁLIA}

A juventude urbana brasileira do início dos anos 1960, influenciada pela contracultura internacional, estava cada vez mais transgressora e engajada nos movimentos políticos e culturais: "a juventude acreditava e se empenhava, com o maior entusiasmo, numa forma peculiar de engajamento cultural diretamente relacionada com as formas de militância política” (HOLLANDA, 2004, p. 19). Desse modo, utilizavam a arte como meio de luta e como significado de poder. 
A poesia marginal, assim nomeada pelas suas características desviantes dos padrões morais e estéticos, surgiu nessa época conturbada, sendo antecedida pelo Centro Popular de Cultura e pelo movimento tropicalista. O CPC, como ficou conhecido, surgiu oficialmente em 1962 a partir de seu manifesto revolucionário, sendo que nessa época o Brasil começava a vivenciar uma constante crise da modernidade com a industrialização, a necessidade de valorizar os produtos internos e a exportação (HOLLANDA, 2004, p. 100-101).

Nessa mesma perspectiva, entre 1967 e 1968 surgiu o movimento Tropicalista. Ora apresentado como a face brasileira da contracultura internacional (influenciado pelos movimentos culturais e políticos no cenário externo, tais como a guerra do Vietnã, a onda hippie nos Estados Unidos, a cultura pop internacional, as bandas inglesas Beatles e Rolling Stones, além do uso de drogas como sinal de libertação e rebeldia), ora apresentado como o ponto de convergência das vanguardas artísticas nacionais (Antropofagia modernista, Poesia Concreta e Bossa Nova), o Tropicalismo foi "consagrado como ponto de clivagem ou ruptura, em diversos níveis: comportamental, político-ideológico, estético" (NAPOLITANO, VILLAÇA, 1998, p. 53).

O Tropicalismo criticava a militância de esquerda (CPC) em suas músicas, uma vez que estes, com seu discurso de arte revolucionária os criticavam por usar os canais de massa como veículo para difundir suas obras. Suas características principais estavam impregnadas na forma de viver dos seus seguidores. O uso de drogas, o erotismo, os comportamentos subversivos eram uma maneira de criticar a repressão vivida na época da ditadura. (HOLLANDA, 2004, p. 69)

Tanto o CPC quanto o Tropicalismo e a marginalia estavam imbuídos de ímpeto revolucionário e transgressor. No entanto, a simples vontade de expressar a transgressão não faz da obra um aparelho de manifestação política, pois o que a torna revolucionária é a técnica que a produz. Enquanto o CPC, ligado à União Nacional dos Estudantes, promoveu a luta política através da arte engajada, e a Tropicália inseriu-se na indústria cultural, a poesia marginal optou pelo underground e pelo desbunde:

Ponto final da viagem contracultural iniciada pela geração beat, passando pelos hippies, a galera do desbunde aprontou mil e umas. Radical como o seu avesso (censura \& repressão), o desbunde - ainda que, dizem, por linhas tortas - colocou em xeque valores poderosos como a racionalidade, a autoridade, a propriedade, o belicismo ( $\varepsilon$ o beletrismo) e pontificou outros como o prazer, o lúdico, o comunitário. A liberação do corpo tange não só o sexual, mas a moda, os gestos, as drogas - o comportamento e o cotidiano, em geral (SALGUEIRO, 2002, p. 30). 
O desbunde surge com o intuito de negar os valores morais cristãos e burgueses da época. Assim, os marginais não somente escrevem em seus poemas o descontentamento vivido, senão também vivem a marginalidade ao utilizar drogas pela proporção de fuga da realidade, ao escutar rock em vez de pegar em armas ou se engajar em partidos políticos. Suas atitudes negam as atitudes do burguês, "homem branco, heterossexual, adulto, civilizado, 'não-poeta', governista, empresário, careta, militar, etc" (SALGUEIRO, 2002, p. 62). Este torna-se, segundo Salgueiro, o representante do lado não marginal, portanto, adversário do pensamento comum entre os poetas. O burguês é aquele que anda segundo os regulamentos do Estado e conforme os seus interesses, sem preocupação com os do povo.

A juventude marginal, recusando a interferência do Estado e da indústria cultural, por negaremse a viver de acordo com os padrões impostos por aqueles que mantinham o poder e a repressão, e coagida pelo controle do conhecimento nas universidades, buscou saídas viáveis: "É exatamente num momento em que as alternativas fornecidas pela política cultural oficial são inúmeras que os setores jovens começarão a enfatizar a atuação em circuitos alternativos ou marginais" (HOLLANDA, 2004, p. 107).

Com a capitalização das produções culturais crescendo fortemente no âmbito dos editoriais, e consequentemente o controle do Estado sobre essas produções, os marginais optaram pela poesia produzida artesanalmente. Destarte, por essa opção esta geração ficou conhecida como "geração mimeógrafo", já que a produção das obras era feita no mimeógrafo, um tipo de copiadora utilizada antigamente nas escolas; ferramenta bem precária que, no entanto, fez jus às propostas vividas pelos "marginais". A distribuição destes materiais era feita nos barzinhos, pequenos shows, teatros, cinemas, nas ruas e entre os poetas. Por esse tipo de produção eles foram muito criticados, tanto pela indústria cultural, quanto pela academia, que rotularam a poesia marginal e sua produção de "literatura do lixo ou lixeratura" (PEREIRA, 1989, p. 74).

O fato de serem criticados de forma tão grotesca, segundo Hollanda, é pela falta de compreensão da proposta desse tipo de produção, pois o princípio programático exigido pelos críticos para uma obra ser considerada literatura “deve ser buscado na própria ausência de programa do grupo, vista como recusa a perspectivas finalistas que incorporem a dinâmica da história e, consequentemente, a utopia" (HOLLANDA, 2004, p. 113). 
É imprescindível esclarecer que os próprios poetas não se intitulavam como "marginais", senão que foram ganhando esse título pelo estilo de vida que levavam e pelo método de produzir suas obras. Assim, muitas vezes o termo é até ironizado, como no poema de Chacal:

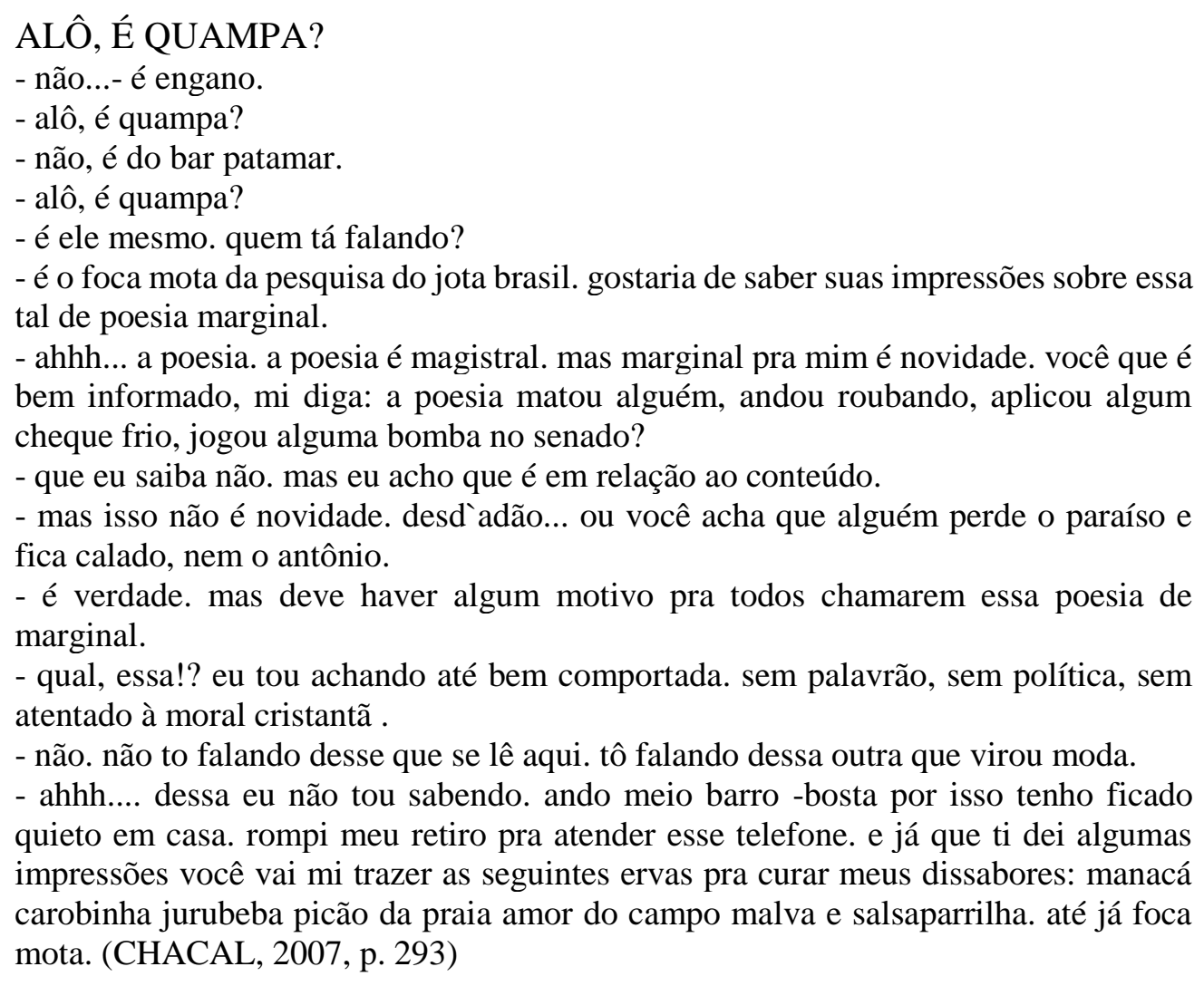

Por essas características, a juventude marginal se destacou de sua geração ao buscar alternativas que não levassem à militância e ao rótulo de programas políticos ou culturais. Pode-se entender que, tanto a geração de 60 quanto a de 70 desejavam fugir das conturbações culturais, políticas e sociais vivenciadas na época, por isso, a arte e o desbunde eram vistos como saídas necessárias.

Outro fato importante para os poetas marginais era rejeitar todo e quaisquer baseamento teórico em suas práticas e produção de suas obras, especificamente dos concretistas. Sobre esta situação, explica Salgueiro:

Entre o cigarro - estamos em pleno carnaval e os exercícios fanologomelopaicos, prevalece o primeiro e a mesma dificuldade do início, reafirmando a postura de relevo antiteórico [...] dos poetas marginais. Ressalta-se, é certo, que se espalhou nos 70, uma espécie de epidérmica e epidêmica concretofobia entre os poetas jovens. Mesmo os mais argutos e experientes, como Armando Freitas Filho, se muniram de uma ferocidade de final de campeonato (SALGUEIRO, 2002, p. 46). 
Outrossim, os poetas se mantinham na margem do conhecimento acadêmico e do movimento concretista por este estar ligado à construção do poema longe dos lirismos confessionais e do cotidiano trivial, sendo que, estas ferramentas são as que mais se observam nas obras da "geração mimeógrafo". Com uma linguagem mais simples, “a recusa das ‘formas sérias do conhecimento’ passa a configurar um traço importante e crítico de uma experiência de descrença em relação à universidade e ao rigor das linguagens técnicas, científicas e intelectuais” (HOLLANDA, 2004, p. 111-112).

\section{O MILAGRE E O VINAGRE}

O recrudescimento da ditadura, após o Ato Institucional $n^{\circ}$ 5, emitido em 13 de dezembro de 1968, foi acompanhado pelo acelerado desenvolvimento dos meios de comunicação de massa, da indústria cultural como um todo e da propaganda do regime militar em particular, o que facilitou a cooptação das classes médias e enfraqueceu a resistência:

[...] a virada da década corresponde a uma nova derrota dos movimentos de massa especialmente o de composição estudantil - e das esquerdas. O chamado 'segundo golpe’ instala definitivamente a repressão política de direita organizada pelo Estado e marca a abertura de um novo quadro conjuntural onde a coerção política irá assegurar e consolidar a euforia do 'milagre brasileiro'. [...] passa-se a viver um clima de ufanismo, com o Estado construindo seus grandes monumentos, pontes e obras faraônicas. (HOLLANDA, 2004, p. 100).

De forma contraditória, no mesmo momento em que o país vivia o tão reverenciado "milagre econômico", viveu também sua época mais conturbada e repressora no contexto cultural, com a prisão de professores, jornalistas e artistas, muitas vezes sendo necessário eles saírem do país para não serem mortos ou encobrir-se seu sumiço. (REIS, 2014, p. 79-92). Antonio Carlos de Brito (Cacaso), no seu poema "Jogos Florais I", tematizou esse contexto sociopolítico:

\footnotetext{
"Minha terra tem palmeiras onde canta o tico-ticoEnquanto isso o sabiá vive comendo o meu fubá. Ficou moderno o Brasil Ficou moderno o milagre a água já não vira vinho, vira direto vinagre." (BRITO, 2007, p. 41).
} 
No poema de Cacaso, no penúltimo verso, o artista faz referência à história da Bíblia cristã, aonde Jesus transforma a água em vinho nas bodas de Canaã (referência), retomando a ideia de "milagre"; no entanto, no último verso transforma-o na bebida que Jesus bebe ao estar pendurado na cruz quase morto (referência), o que indica o vinagre como o resultado final do "milagre econômico", uma bebida que antes parecia vinho, agora é sinal de crise e sofrimento.

Cacaso também se apropria do poema consagrado na primeira fase do Romantismo brasileiro - “Canção do exílio”, do poeta Gonçalves Dias (1846) - e constrói uma paródia, uma vez que o poema romântico simboliza a saudade daquele que está longe da pátria amada, evocando suas mais diversas qualidades.

Na passagem dos anos 1960 para os 1970, quando o Brasil fruiu um período de intenso desenvolvimento econômico, o Estado desejou a todo custo ganhar o público burguês de classe média, enchendo-o de mimos e novidades internacionais, não somente no consumismo de bens duráveis e semiduráveis, mas também nos campos das artes e da indústria cultural. A situação foi ironizada no poema "Três números de mágica", de Leila Miccolis:

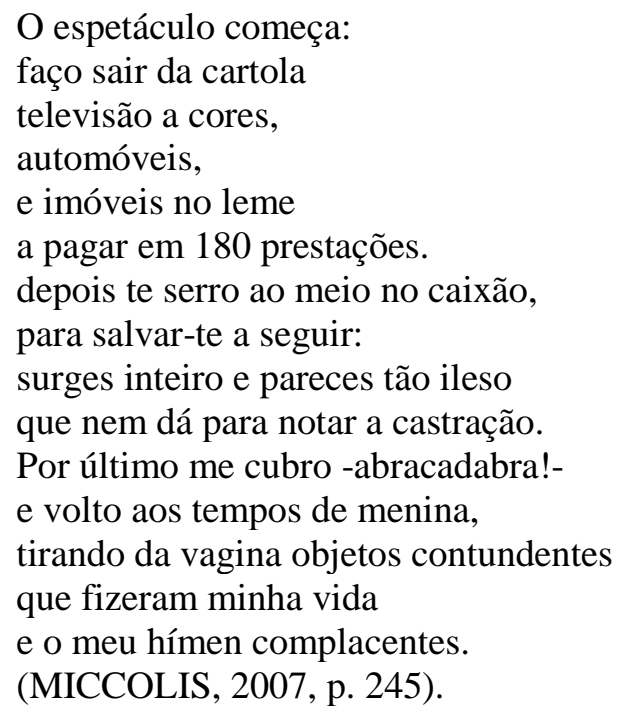

Os poetas marginais, com humor e com medo, nos oferecem um diagnóstico da repressão vivida sob os anos de chumbo. Em tal diagnose, é possível identificar que, no sufoco da ditadura, a geração mimeógrafo não buscava o caminho da liberdade na luta armada, como agiam os guerrilheiros, tampouco nas luzes do Esclarecimento, como podemos ler no poema “Luz”, de Francisco Alvim: 


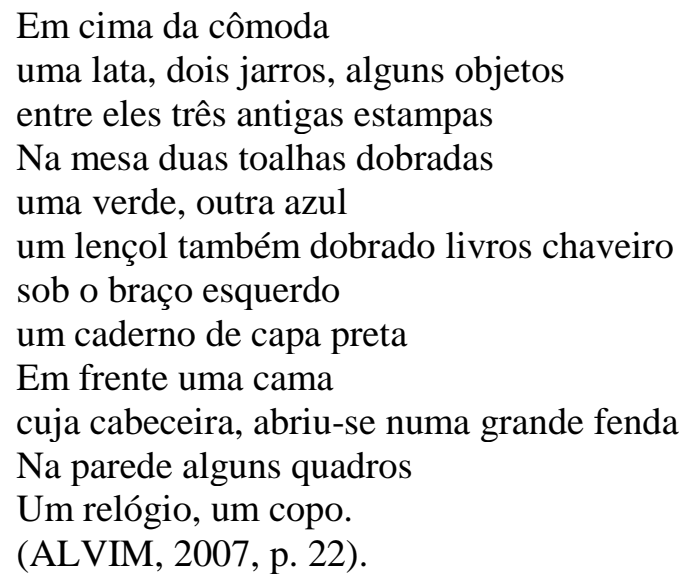

O detalhamento de cada item forma imagens que o leitor avista, tornando-se o poema uma série de fotografias ou um tipo de vídeo em câmera lenta num pequeno quarto. Objetos que participam de modo a compor o cotidiano de qualquer cidadão se convertem em objetos que compõem um poema. Ao utilizar-se dessa linguagem simples e desses elementos, o poeta se torna o mediador entre leitor e poema, de maneira que os dois se encontram numa mesma dimensão. "É a poetização de uma vivência, é a poetização da experiência do cotidiano e não o cotidiano poetizado" (HOLLANDA, 2004, p. 112). Destarte, o cotidiano, ao invés de ser desprezado, passa a ser visto como um pano de fundo para uso do poeta, tornando-se justamente o instrumento principal para a poesia cumprir o seu papel de arte; diferentemente da intelectualidade acadêmica de outrora, que insistia em manter a poesia em sua "torre de marfim".

Da mesma forma, a crítica ao estado de repressão e a perda de liberdade nas obras marginais se reflete através do uso de alegorias e o uso do humor sarcástico, estratégia de dissimulação empregada para refletir as manifestações da contracultura sem levantar suspeitas da sua crítica. Como manifesta Carlos Saldanha, em seu poema "Sonatina Italiana":

\author{
A donzela órfã \\ Seduzida e abandonada \\ Soluça na neve \\ O velho sabujo \\ De cartola de veludo \\ Olha de longe... \\ E gargalha \\ Foi ele que a desgraçou. \\ Mas bêbado e cético \\ Pouco se importa. \\ E gargalha: Ak Ah Ah... \\ (SALDANHA, 2007, p. 27).
}


A partir desse poema, analisa-se que a "donzela órfã" pode ser interpretada como o Brasil composto pelos seus cidadãos e o "velho sabujo" sendo o Estado repressor que a corrompeu. O poeta compara o Brasil a uma mulher delicada e órfã que era virgem até ser violentada e desgraçada pelo “velho", ou seja, o Estado de Exceção instaurado em 1964. Entende-se que depois do autoritarismo do Estado não há mais preocupação em ser "sabujo", servil, "puxa-saco" com a população, agora podese rir da infelicidade do Brasil, privar-lhe de sua liberdade. Da mesma forma, Torquato Neto enfatiza ainda mais a crítica contra a ditadura, desta vez num tom grave:

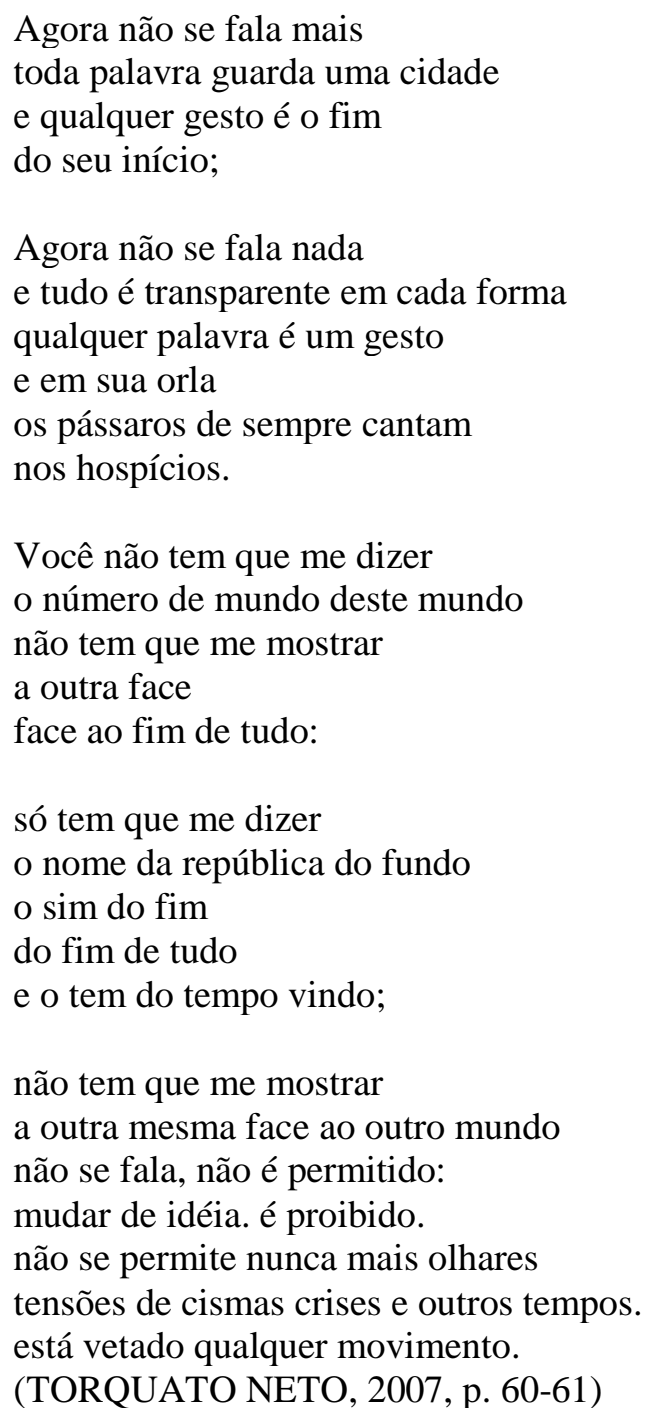

Torquato Neto expressa em seus versos as palavras que não podem ser pensadas, ouvidas e muito menos ditas. Com seu poema, externaliza suas dores; seus sentimentos aprisionados tomam conta do poema desde os primeiros versos, assim, ele passa a ser o porta voz de todos aqueles que se 
sentem presos em suas rotinas sem liberdade. A crítica é totalmente direcionada ao sentimento de proibição do pensamento; em seus últimos versos "mudar de ideia é proibido", "não se permite nunca mais olhares", “está vetado qualquer movimento" Torquato toma o lugar do opressor e transmite seu discurso, de maneira a criticá-lo.

Outro fator que influenciou na escrita dos poetas foi a transgressão de valores morais através das obras e das atitudes, de forma a causar estranhamento para o leitor. Geralmente, nas obras dos poetas marginais o uso de palavras de baixo calão é constante, assim como obscenidades ou críticas corrosivas. Observe-se neste poema de Roberto Schwarz, intitulado "Conto de Fadas": "O ratão transformara-se num príncipe encantado de pau duro. / A bocetinha falante de Cinderela babava pelos bigodes.” (SCHWARZ, 2007, p. 90). Também merece menção o poema “Arpejos 1”, de Ana Cristina Cesar:

Acordei com uma coceira terrível no hímen. Sentei no bidê com um espelhinho e examinei minuciosamente o local. Não surpreendi indícios de moléstia. Meus olhos leigos na certa não percebem que um rouge a mais tem um significado a mais. Passei uma pomada branca até que a pele (rugosa e murcha) ficasse brilhante. Com essa murcharam igualmente meus projetos de ir de bicicleta à ponta do Arpoador. O selim poderia reavivar a irritação. Em vez decidi me dedicar à leitura. (CESAR, 2007, p. 143).

Os dois autores acima citados possuem as mesmas características da transgressão da palavra, uma vez que esta é utilizada como ferramenta de crítica social através da transgressão que ela transmite, principalmente para a sociedade conservadora. Desta forma, os autores se utilizam de termos como "pau duro", "bocetinha" e "hímen" para criar o estranhamento e a polêmica a partir de temas tabus, não discutidos ou simplesmente não falados na sociedade.

Na leitura dos poemas de Ana Cristina Cesar e de Leila Miccolis (citado anteriormente), evidencia-se o elemento "hímen" como fator comum, sendo este o órgão que define uma mulher que nunca teve relações sexuais, assim, pode-se dizer que as duas autoras escolheram este elemento de forma a criticar a sociedade e seus falsos valores morais, já que esta se preocupava com as palavras chulas e não com os problemas do país que desmoronava no quintal.

Com todas essas características encontradas nas obras dos poetas marginais dentro da antologia 26 poetas hoje, organizada por Heloisa Buarque de Hollanda, deve-se analisar a grande iniciativa de oferecer alternativas através da arte para aqueles que jaziam presos dentro de si por causa da repressão. 
É necessário ressaltar o provincianismo da antologia organizada por Hollanda, que abrange apenas os poetas do eixo Rio-São Paulo, não obstante a marginalia ter alcançado outras regiões do país. Na região norte, por exemplo, merece menção o poeta marginal Binho (pseudônimo de Rubens Vaz Cavalcante), de Porto Velho, Rondônia. Na obra Poukas \& roukas \& loukas, mimeografada em 1982, Binho nos mostra as influências da marginália na Amazônia:

\author{
enquanto me matavas \\ nasciam milhares de poetas \\ marginais \\ prá te infernizarem a vida \\ mas que koisa louka \\ fikar olhando o rio \\ a ver navios \\ sakando os botos \\ kurtindo o cio \\ (BINHO, 1982, s. p.).
}

Podem-se observar nos versos do escritor rondoniense as marcas do movimento marginal com toques típicos da região, como a presença do boto e do, assim como a presença de imagens que ilustram os poemas e as temáticas; tudo isso impresso em mimeógrafo. Desta forma, registra-se o grande espaço que tiveram os movimentos contraculturais e sua aderência na juventude das outras regiões.

A poesia como arte libertadora, nos leva a refletir sobre seu papel político na sociedade. A luta da poesia marginal, assim como dos movimentos de contracultura contra o sistema opressor fazem, atualmente, desses meios uma forma de nos conscientizar para que barbáries como as causadas pelas ditaduras na América e no mundo não se repitam. Como disse recentemente um dos expoentes da geração mimeógrafo: “a luta continua até o fim” (CHACAL, 2018, s. p.).

\title{
CONSIDERAÇÕES FINAIS
}

Com esta pesquisa, pode-se concluir que o objetivo último da poesia marginal não deveria ser formar o gosto estético dos leitores, mas sim resistir à opressão do autoritarismo de Estado. Os poetas marginais e aqueles que fizeram parte da construção da marginalia como um todo nos levam a refletir 
sobre as barbáries que aconteceram e acontecem no mundo todo, além de nos trazer a esperança da arte como ferramenta de escape para o sofrimento da humanidade.

A arte e a literatura foram para a juventude dos anos 1960 e 70 grandes apoios em meio ao caos que se instaurou, e não somente para os jovens dessa época, senão também para todos aqueles que se viram desgraciados com eventos deploráveis causados por aqueles que estavam no poder. É graças a movimentos como a marginália, o Tropicalismo e o CPC que foram suportáveis as represálias e a falta de liberdade de pensamento na época da ditadura. Da mesma forma, os poemas, com seu teor testemunhal nos levam a refletir que eventos como esses não podem mais se repetir. Por outro lado, este trabalho possibilitou o estudo histórico dos acontecimentos na ditadura militar brasileira a partir de 1964, assim como os diferentes movimentos culturais que agitaram as ruas do Brasil.

O teor histórico da poesia marginal nos leva a analisar os problemas políticos, existenciais e socioculturais que se alastraram nos anos de chumbo. Ao buscar alternativas contra as estruturas de dominação, a "geração mimeógrafo" inventou saídas para as dores vividas pelo estado de repressão através do humor, a ironia e a paixão.

\section{REFERÊNCIAS}

ALVIM, Francisco. Luz. In: HOLLANDA, Heloisa Buarque de. 26 poetas hoje. $6^{\text {a }}$ ed. Rio de Janeiro: Aeroplano Editora, 2007, p. 22.

BAUDELAIRE, Charles. Sobre a modernidade: o pintor da vida moderna. Organização de Teixeira Coelho. Rio de Janeiro: Paz e Terra, 1996.

BINHO [Rubens Vaz Cavalcante]. Poukas \& Roukas \& Loukas. Porto Velho, RO: Edição do autor, 1982. 18 p. Mimeografado.

BRITO, Antonio Carlos de. Jogos florais I. In: HOLLANDA, Heloisa Buarque de. 26 poetas hoje. $6^{\mathrm{a}}$ ed. Rio de Janeiro: Aeroplano Editora, 2007, p. 41.

CESAR, Ana Cristina. Arpejos. In: HOLLANDA, Heloisa Buarque de. 26 poetas hoje. $6^{\mathrm{a}}$ ed. Rio de Janeiro: Aeroplano Editora, 2007, p. 143.

CHACAL, Ricardo. A resistência do bicho tinhoso. Jornal Rascunho, Curitiba, n. 217, s. p., maio de 2018. Disponível em: <http://rascunho.com.br/a-resistencia-do-bicho-tinhoso/>. Acesso em: 03 ago. 2018. 
CHACAL, Ricardo. Belvedere [1971-2007]. Rio de Janeiro: 7 Letras, 2007.

DIAS, A. Gonçalves. Primeiros cantos: poesia. Rio de Janeiro: Laemmert, 1846.

HENRIQUES NETO, Afonso. Roteiro da poesia brasileira: anos 70. 1 ed. São Paulo: Global, 2009.

HOLLANDA, Heloisa Buarque de. 26 poetas hoje. $6^{a}$ ed. Rio de Janeiro: Aeroplano Editora, 2007.

HOLLANDA, Heloisa Buarque de. Impressões de viagem: CPC, vanguarda e desbunde: 1960/1970. Rio de Janeiro: Aeroplano, 2004.

MICCOLIS, Leila. Três números de mágica. In: HOLLANDA, Heloisa Buarque de (org.). 26 poetas hoje. Rio de Janeiro: Aeroplano, 2007, p. 45.

NAPOLITANO, Marcos; VILLACA, Mariana Martins. Tropicalismo: As Relíquias do Brasil em Debate. Revista Brasileira de História, São Paulo, v. 18, n. 35, p. 53-75, 1998.

OITICICA, Hélio. Seja Marginal, Seja Herói. In: ENCICLOPÉDIA Itaú Cultural de Arte e Cultura Brasileiras. São Paulo: Itaú Cultural, 2018. Disponível em: <http://enciclopedia.itaucultural.org.br/obra2638/bandeira-poema-seja-marginal-seja-heroi>. Acesso em: 05 de Ago. 2018.

PEREIRA, Carlos Alberto Messeder. Retrato de época: poesia marginal, anos 70. Rio de Janeiro: Funaré, 1981.

REIS, Daniel Aarão. Ditadura e democracia no Brasil: do golpe de 1964 à Constituição de 1964 à Constituição de 1988. Rio de Janeiro: Zahar, 2014.

SALDANHA, Carlos. Sonatina Italiana. In: HOLLANDA, Heloisa Buarque de (org.). 26 poetas hoje. Rio de Janeiro: Aeroplano, 2007, p. 27.

SALGUEIRO, Wilberth Clayton Ferreira. Forças e formas: aspectos da poesia brasileira contemporânea (dos anos 70 aos 90). Vitória: Edufes, 2002.

SAMPAIO, Sérgio. Tem que acontecer. Continental, 1976. 1 disco sonoro.

SCHWARZ, Roberto. Conto de fadas. In: HOLLANDA, Heloisa Buarque de (org.). 26 poetas hoje. Rio de Janeiro: Aeroplano, 2007, p. 90.

SIMON, Iumna Maria; DANTAS, Vinícius. Poesia ruim, sociedade pior. Novos Estudos Cebrap, São Paulo, n. ju 1985, p. 48-61, 1985. 
TORQUATO NETO. [sem título]. In: HOLLANDA, Heloisa Buarque de (org.). 26 poetas hoje. Rio de Janeiro: Aeroplano, 2007, p. 60-61.

Recebido em 05/08/2018

Aceito em 29/12/2018 